\title{
Ventilation/perfusion SPECT/CT findings in different lung lesions associated with COVID-19: a case series
}

\author{
Nina Cobes ${ }^{1} \cdot$ Mohamed Guernou $^{1} \cdot$ David Lussato $^{1} \cdot$ Mathieu Queneau $^{1} \cdot$ Bernard Songy $^{1} \cdot$ Gérald Bonardel $^{1}$. \\ Jean-François Grellier ${ }^{1}$
}

Received: 25 April 2020 / Accepted: 7 June 2020 / Published online: 18 June 2020

(C) Springer-Verlag GmbH Germany, part of Springer Nature 2020

\begin{abstract}
Purpose The aim of this series of cases is to show the aspects of ventilation/perfusion single-photon emission computed tomography combined with computed tomography (V/Q SPECT/CT) in patients hospitalized for COVID-19 pneumonia, with the worsening of respiratory symptoms raising the suspicion of a pulmonary embolism. Patients did not benefit from CT angiography for various reasons: a contraindication, unavailability of the CT angiography, or a low clinical probability for pulmonary embolism.

Methods We retrospectively describe the results of the V/Q SPECT/CT of five patients hospitalized for COVID-19 pneumonia in the nuclear medicine departments of the Centre Cardiologique du Nord and of the Delafontaine hospital in Saint-Denis (Ile-deFrance, France) between April 2, 2020, and April 10, 2020. These patients had persistent dyspnea or chest pain suggesting pulmonary embolism.

Results The V/Q SPECT/CT allowed to diagnose a pulmonary embolism in one of these five patients. We also noted several characteristics of the perfusion and ventilation depending on the lung lesions on the CT scan. The areas affected by COVID-19 were most often responsible for ventilatory anomalies with a relatively preserved perfusion. In more advanced cases of pneumonia, with alveolar fillings, the perfusion was also reduced or absent in accordance with large ventilation defects. In addition, the healthy parenchyma appeared to benefit from an uptake in ventilation and perfusion.

Conclusion V/Q SPECT/CT can play a role in the management of patients hospitalized for COVID-19 for the diagnosis of embolic complications with meticulous hygienic precautions. The different characteristics of the ventilatory and perfusion anomalies related to COVID-19 pneumonia will be confirmed with the next cases. In addition, in this pandemic context and facing a significant infectious risk, the utility of ventilation will also have to be specified.
\end{abstract}

Keywords COVID-19 $\cdot$ Pulmonary embolism $\cdot$ V/Q SPECT $\cdot$ Coagulopathy

\section{Introduction}

Outbreaking in December 2019, the epidemic related to the new coronavirus of severe acute respiratory syndrome (SARS-CoV2), identified in the city of Wuhan, Hubei Province in China, is now spreading around the world [1].

This article is part of the Topical Collection on Infection and inflammation

Nina Cobes

nina.cobes@gmail.com

1 Imagerie Moléculaire et Fonctionnelle - Centre Cardiologique du Nord - Hôpital Delafontaine, Saint-Denis, France
Although most often responsible for mild symptoms, the infection, also called COVID-19, can cause severe pneumonia [2]. Patients hospitalized for respiratory distress due to COVID-19 can develop multiple complications, including coagulation disorders. This is linked both to the conditions of prolonged bed rest and to the coagulopathy caused by the infection [3] with a major thromboembolic risk (deep vein thrombosis (DVT) and pulmonary embolism (PE)) [4]. Several cases of PE were thus reported and diagnosed through $\mathrm{CT}$ angiography [5].

It is in this context that the ventilation/perfusion singlephoton emission computed tomography combined with computed tomography (V/Q SPECT/CT) can be used to search for a pulmonary embolism complication in patients with COVID19 pneumonia. 
We retrospectively present here five cases of V/Q SPECT/CT performed in patients with COVID-19, referred for worsening of dyspnea or chest pain raising suspicion of PE. They benefited from their V/Q SPECT/CT between April 2 and April 10, 2020, in the nuclear medicine departments of the Centre Cardiologique du Nord and of the Delafontaine hospital in Saint-Denis, Ile-de-France, France.

\section{Methods}

V/Q scans were performed using hybrid SPECT-CT cameras (GE Optima NM/CT 640 and GE Discovery; GE Healthcare) with injection of Technetium ${ }^{99 \mathrm{~m}} \mathrm{Tc}$ macro-aggregated albumin for the perfusion and inhalation of either ${ }^{81 \mathrm{~m}} \mathrm{Kr}$-Krypton or Technegas ${ }^{\circledR}$ for the ventilation.

Specific protocol and circuit for COVID-19 patients had been implemented:

\section{Precautions before performing V/Q SPECT/CT:}

V/Q SPECT/CT were all performed on a time slot dedicated to COVID-19 positive patients, at the end of the day. No more non-COVID patients were present in the department, and no examination was scheduled at the same time or after. No more than two COVID patients per day.

The patients did not station in the hallways and wore a mask on arrival in the department.

\section{Preparation of the examination room:}

We had established a delimitation with "clean areas" and "contaminated areas" in contact with the patient. Material unnecessary for the exam was removed from the room. The bin for contaminating objects was placed at the entrance of the room. The room and the equipment were decontaminated before and after each patient.

\section{Dressing of the personnel:}

The personnel had to wear high-protection clothing combining an FFP2 mask, a disposable overcoat, overshoes, a cap, protective glasses, and two pairs of non-sterile gloves. Protective clothing was changed after each patient. One manipulator was in charge of the console, and another one was in contact with the patient.

\section{Perfusion:}

A syringe of Technetium ${ }^{99 \mathrm{~m}} \mathrm{Tc}$ macro-aggregated albumin $\left({ }^{99 \mathrm{~m}} \mathrm{Tc}-\mathrm{MAA}\right)$ was prepared just before the patient arrived and then injected in the supine position to avoid sedimentation of macroaggregates into the lung bases. The doses injected depend on the ventilation tracers used: $185 \mathrm{MBq}$ for Krypton and $240 \mathrm{MBq}$ for Technegas ${ }^{\circledR}$.

5. Ventilation:

a. Krypton $81 \mathrm{~m}$

We used a new ventilation kit with disposable masks and tubes. The kit includes a disposable filter between the mask and the tubing set containing a bidirectional membrane to prevent cross-contamination. According to the supplier, the filter is supposed to be $99.9 \%$ effective in stopping bacteria and viruses. After the filter, a tube with two-way valves directs, on the one hand, the flow of Krypton air from the generator to the patient and, on the other hand, the exhaled air from the patient's lungs to the ventilation unit. This part of the tubing set is also for single use and was changed after each patient.

\section{b. Technegas ${ }^{\circledR}$}

Gas particles were inhaled through a hose and a mouthpiece containing a filter. The mouthpiece and filter were disposable and changed between each patient. A suction bell was located above the patient to prevent the spread of aerosols. Hose disinfection was realized before and after each patient.

\section{CT parameters:}

The following scanner settings were applied: $120 \mathrm{keV} /$ $148 \mathrm{mAs}$, spacing $1.25 \mathrm{~mm}, 512 \times 512$ matrix.

\section{Room disinfection:}

Application of a decontaminant on the examination table, the machine, and the patient's environment, leaving to act for 15 min after each patient.

\section{Results}

\section{Case 1 (Fig. 1)}

The first case was a 53-year-old man with dyspnea, tachycardia (heart rate (HR) $120 \mathrm{bpm}$ ), and a typical electrocardiographic appearance of $\mathrm{S}_{1} \mathrm{Q}_{3}$ with extended $\mathrm{S}$ wave in lead I and $\mathrm{Q}$ wave in lead III. Clinical parameters and laboratory data of the patient are available on Table 1.

V/Q SPECT/CT found a segmental pulmonary embolism with a mismatch perfusion defect of the apical segment of the 
Table 1 Clinical and laboratory data of the five patients

\begin{tabular}{|c|c|c|c|c|c|}
\hline Patients & Case 1 & Case 2 & Case 3 & Case 4 & Case 5 \\
\hline Age (years) & 53 & 71 & 63 & 40 & 69 \\
\hline Sex & Man & Man & Man & Man & Woman \\
\hline $\begin{array}{l}\text { Indication of V/Q } \\
\text { SPECT/CT }\end{array}$ & $\begin{array}{l}\text { Dyspnea } \\
\text { Tachyca- } \\
\text { rdia }\end{array}$ & $\begin{array}{l}\text { Dyspnea under } \\
\text { oxygen } \\
\text { therapy }\end{array}$ & $\begin{array}{l}\text { Dyspnea under } \\
\text { oxygen } \\
\text { therapy }\end{array}$ & $\begin{array}{l}\text { Dyspnea } \\
\text { Tachycardia } \\
\text { Chest pain }\end{array}$ & $\begin{array}{l}\text { Dyspnea under } \\
\text { oxygen } \\
\text { therapy }\end{array}$ \\
\hline $\begin{array}{l}\text { Indication for } \mathrm{V} / \mathrm{Q} \\
\text { SPECT/CT in- } \\
\text { stead of CT an- } \\
\text { giography }\end{array}$ & $\mathrm{AKI}$ on $\mathrm{CKI}$ & AKI & $\begin{array}{l}\text { Disponibility of } \\
\text { the } \\
\text { scintigraphy }\end{array}$ & $\begin{array}{l}\text { Low } \\
\text { probabili- } \\
\text { ty of PE }\end{array}$ & $\begin{array}{l}\text { Low probability } \\
\text { of PE }\end{array}$ \\
\hline $\begin{array}{l}\text { Diagnosis of } \\
\text { COVID-19 }\end{array}$ & $\begin{array}{l}\text { PCR } \\
\text { positive }\end{array}$ & $\begin{array}{r}\text { Clinical and CT } \\
\text { scan findings }\end{array}$ & PCR positive & $\begin{array}{l}\text { PCR } \\
\text { positive }\end{array}$ & PCR positive \\
\hline $\begin{array}{l}\text { Days of } \\
\text { hospitalization }\end{array}$ & 13 & 5 & 4 & 20 & 11 \\
\hline $\begin{array}{l}\text { Anticoagulant } \\
\text { therapy }\end{array}$ & Preventive & None & None & Preventive & Preventive \\
\hline D-dimers $(\mu \mathrm{g} / \mathrm{mL})$ & $\begin{array}{l}\text { Not } \\
\quad \text { available }\end{array}$ & $>20,000$ & Not available & 907 & 330 \\
\hline $\begin{array}{l}\text { DVT (Venous } \\
\text { Doppler US of } \\
\text { lower limb or } \\
\text { clinical } \\
\text { suspicion) }\end{array}$ & $\begin{array}{l}\text { No clinical } \\
\text { suspicion }\end{array}$ & $\begin{array}{l}\text { No clinical } \\
\text { suspicion }\end{array}$ & $\begin{array}{l}\text { Venous Doppler } \\
\text { US negative }\end{array}$ & $\begin{array}{l}\text { No clinical } \\
\text { suspicion }\end{array}$ & $\begin{array}{l}\text { Venous } \\
\text { Doppler US } \\
\text { negative }\end{array}$ \\
\hline Oxygen therapy & No & $15 \mathrm{~L}$ & $15 \mathrm{~L}$ & $4 \mathrm{~L}$ & $2 \mathrm{~L}$ \\
\hline Clinical & $98 \%$ & $97 \%$ & $82 \%$ & $95 \%$ & $96 \%$ \\
\hline $\begin{array}{l}\text { parame- } \mathrm{HR} \\
\text { ters }\end{array}$ & $120 \mathrm{bpm}$ & $100 \mathrm{bpm}$ & $100 \mathrm{bpm}$ & $90 \mathrm{bpm}$ & 87 bpm \\
\hline
\end{tabular}

$A K I$ acute kidney injury, $C K I$ chronic kidney injury, $S p O_{2}$ oxygen saturation, $H R$ heart rate, $P C R$ polymerase chain reaction technique, US ultrasound right lower lobe, representing an amputation of the total pulmonary vascular bed of approximately $5 \%$.

CT scan showed moderate COVID-19 pulmonary involvement (25-50\% of total volume), mainly consisting of subpleural ground glass and rare interlobular reticulations. These areas of hyperdensity, few in number, appeared correctly perfused, and ventilated.

\section{Case 2 (Fig. 2)}

The second case was a 71-year-old man with an increase of dyspnea under oxygen therapy. On arrival in the nuclear medicine department, the HR was $100 \mathrm{bpm}$ and the oxygen saturation under $15 \mathrm{~L}$ per minute at $97 \%$. Laboratory test showed a significant increase in D-dimers $(>20,000 \mu \mathrm{g} / \mathrm{mL})$. All the
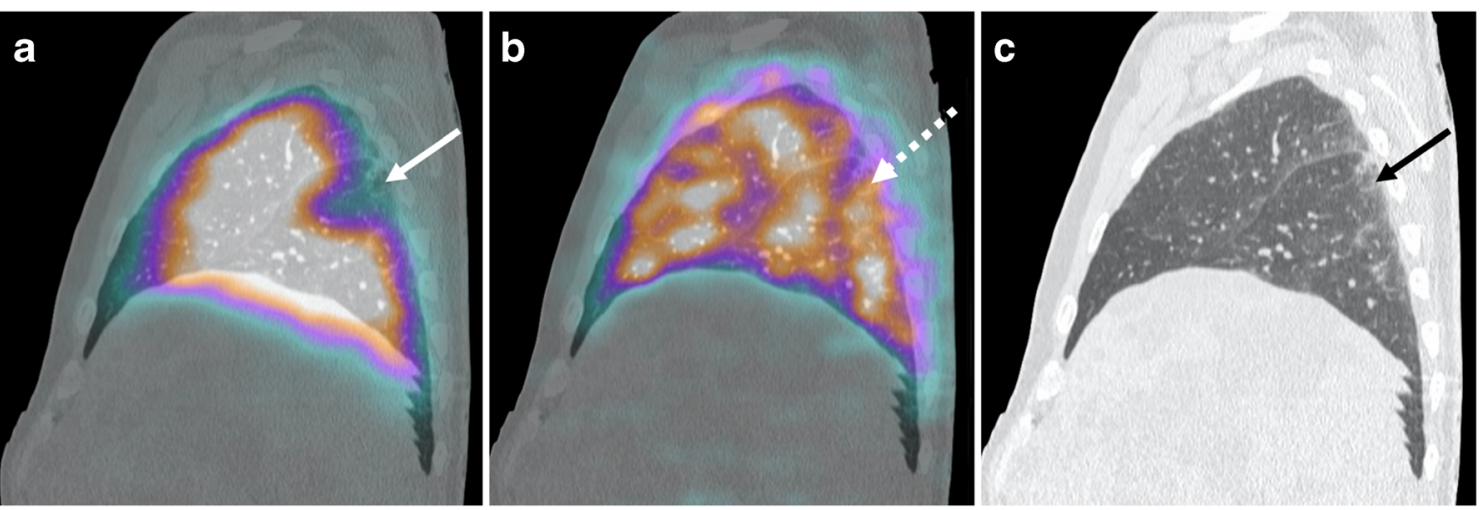

Fig. 1 a Sagittal fused perfusion SPECT and CT (240 MBq of Pulmocis $\left.{ }^{\circledR}\right)$. b Sagittal fused ventilation SPECT and CT (148 MBq of Technegas $\left.{ }^{\circledR}\right)$. c Sagittal CT scan. Perfusion defect with pleural triangular base of the apical segment of the right lower lobe (white arrow) with normal ventilation in correspondence (white dotted arrow). CT scan shows sub-pleural ground glass predominant in the lower lobes (black arrow) 

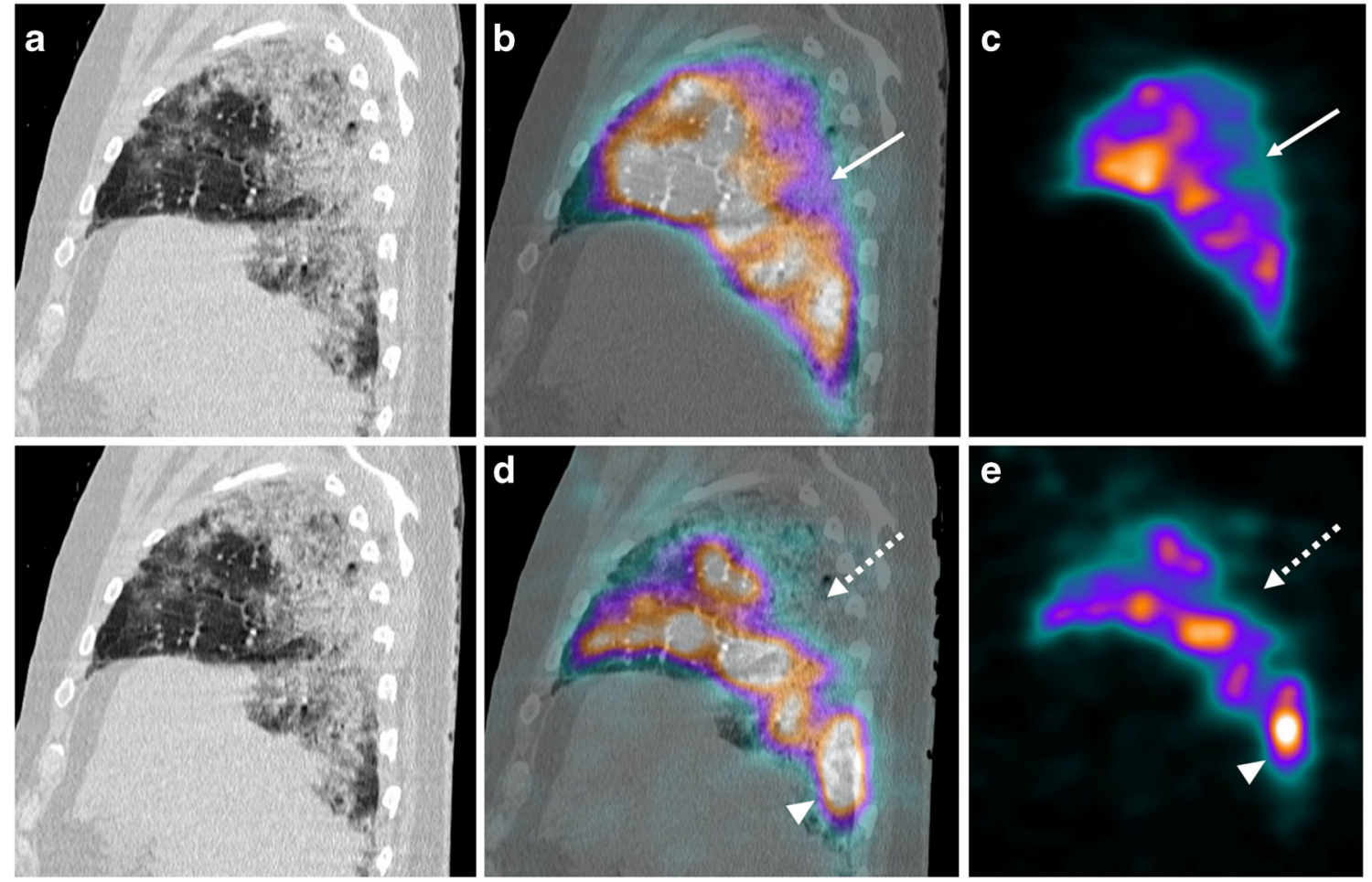

Fig. 2 a Sagittal CT scan. b Sagittal fused perfusion SPECT and CT (240 MBq of Pulmocis®). c Sagittal perfusion SPECT. d Sagittal fused ventilation SPECT and CT (148 MBq of Technegas $\left.{ }^{\circledR}\right)$. e Sagittal ventilation SPECT. Hypoperfusion zone (white arrow) associated with a complete and very extensive ventilatory defect in the apical segment of

clinical parameters and laboratory data of the patient are available on Table 1.

The V/Q SPECT/CT did not find PE.

Ventilation was very heterogeneous: (1) the hyperdensities areas related to COVID-19 pneumonitis on the CT scan were clearly hypoventilated in scintigraphy with several large ventilatory defects, and (2) there was an accumulation of Technegas ${ }^{\circledR}$ in healthy parenchyma zones.

Compared to ventilation, the perfusion was well preserved; however, (1) it was partially reduced in the areas of ground glass, and (2) hypoperfusion seemed to be more pronounced in areas of denser parenchymal consolidation in accordance with large ventilatory defects.

In this patient, CT scan showed a critical extent of COVID19 pulmonary involvement ( $>75 \%$ of total volume).

\section{Case 3 (Fig. 3)}

The third case was a 63-year-old man referred for worsening of respiratory symptoms under oxygen therapy. On arrival in the nuclear medicine department, the patient had an episode of desaturation to $82 \%$ under $15 \mathrm{~L}$ per minute of oxygen using a high concentration mask. His heart rate was $100 \mathrm{bpm}$.

Clinical parameters and laboratory data of the patient are available on Table 1. the right lower lobe (white dotted arrow) corresponding on the CT scan to an alveolar filling zone. In some areas of pulmonary parenchyma relatively preserved on the $\mathrm{CT}$ scan, there is an accumulation of Technegas ${ }^{\circledR}$ achieving an aspect of "luxury ventilation" (white arrowhead)

The V/Q SPECT/CT did not find PE. Ventilation showed very large defects in the subpleural areas and at the bases, corresponding to COVID-19 pulmonary lesions on the CT scan.

In comparison, the perfusion was relatively well preserved, especially in the areas of consolidation. There were rare defects matched in ventilation and perfusion within the lesions of consolidation. However, in those mixed defects areas, ventilation anomalies were predominant. Note as in the previous case the uptake not only of the ventilation tracer but also of the perfusion tracer in the healthy parenchyma areas.

The CT scan showed an aggravation of the pulmonary lesions in comparison with the CT scan performed 2 days earlier, on April 1, with a critical pulmonary involvement (> $75 \%$ of the parenchyma versus $25-50 \%$ previously). Faced with the worsening of COVID-19 pneumonia, the patient was transferred to intensive care following the completion of his V/Q SPECT/CT.

\section{Case 4 (Fig. 4)}

The fourth case was a 40-year-old man presenting dyspnea with a saturation of oxygen at $95 \%$ under $4 \mathrm{~L}$ of oxygen, associated with tachycardia at $90 \mathrm{bpm}$ and right lower chest pain. 
Fig. 3 a Axial fused perfusion SPECT and CT (185 MBq of Pulmocis () . b Axial Perfusion SPECT. c Axial fused ventilation SPECT and CT (148 MBq of Krypton $\left.{ }^{\circledR}\right)$. d Axial Ventilation SPECT. e Axial CT scan V/Q SPECT/CT April 3. f Axial CT scan April 1. Matched defects (white arrows), dominated by ventilatory anomalies, are located in areas of parenchymal consolidation on the CT scan. There is an accumulation of the perfusion tracer (white dotted arrow) and also of the ventilation tracer (white arrow head) in adjacent healthy parenchyma areas. CT scan shows an increase of the extent of the COVID-19 lesions, now critical ( $>75 \%$ of the total volume). Note the cystic areas (black arrow)
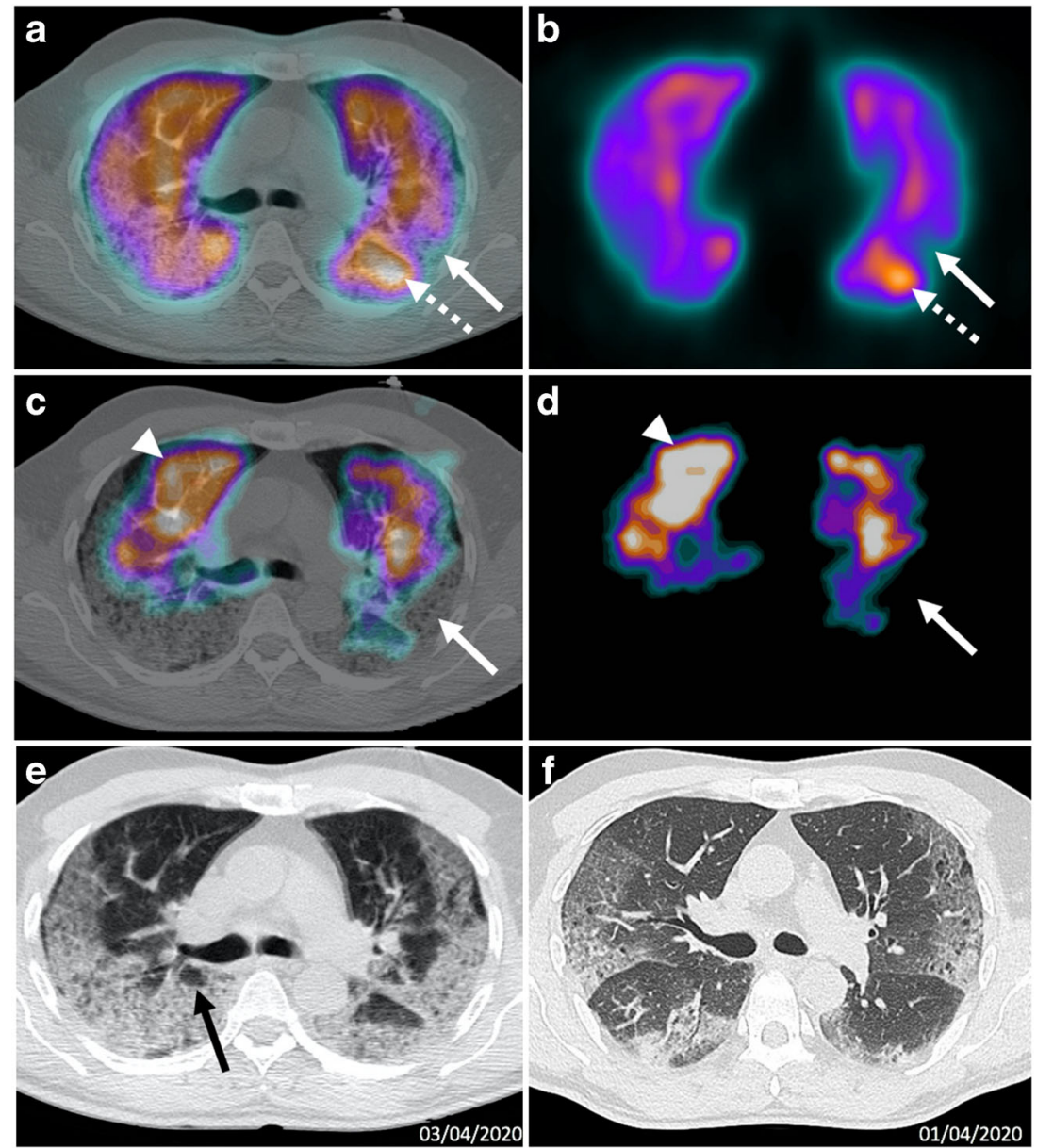

Clinical parameters and laboratory data of the patient are available on Table 1.

The V/Q SPECT/CT did not find PE. There was a heterogeneous perfusion with partial hypoperfusion zones and complete perfusion defects perfectly consistent with ventilation. These matched defects correspond to pulmonary lesions such as consolidations and organized pneumonitis.

CT scan showed a moderate extent of COVID-19 pulmonary involvement (25-50\% of total volume) predominant in the lower lobes.

\section{Case 5 (Fig. 5)}

The fifth case was a 69-year-old woman with persistent dyspnea on oxygen therapy. On arrival in the department, the patient was under $2 \mathrm{~L}$ of oxygen with an oxygen saturation at $96 \%$ and a $\mathrm{HR}$ at $87 \mathrm{bpm}$.

Clinical parameters and laboratory data of the patient are available on Table 1.

V/Q SPECT/CT did not find PE. The perfusion was generally homogeneous and preserved. Pure ventilation anomalies were observed with respect to subpleural ground glass areas. The extent of pulmonary involvement of COVID-19 lung disease on the CT scan was moderate (25-50\% of total volume) mainly consisting in ground glass opacity.

\section{Discussion}

Infection with SARS-CoV2 renamed COVID-19 by the World Health Organization (WHO) [1] is now a pandemic responsible for severe respiratory problems. Soon, the various acute complications impacting the prognosis of hospitalized patients were described, including coagulopathy [3]. Indeed, coagulation disorders are common in respiratory tract infections and have been identified in other SARS viruses [6]. In the same way, during the SARS-Cov2 infection, an important inflammatory syndrome can be observed with the production of pro-inflammatory cytokines and activation of the coagulation factors causing a state of hypercoagulation [7]. A significant increase of D-dimers and fibrin degradation products, suggesting hyperfibrinolysis, has also been observed and associated with a poor prognosis [8]. 
Fig. 4 a Axial fused perfusion SPECT and CT (240 MBq of Pulmocis®). b Axial fused ventilation SPECT and CT (148 MBq of Technegas $\left.{ }^{\circledR}\right)$. $\mathbf{c}$ Axial perfusion SPECT. d Axial ventilation SPECT. e Axial CT scan. Matched defect in perfusion and ventilation of the posterior segment of the right upper lobe (white arrow), compared to an alveolar filling (black arrow) on the scanner
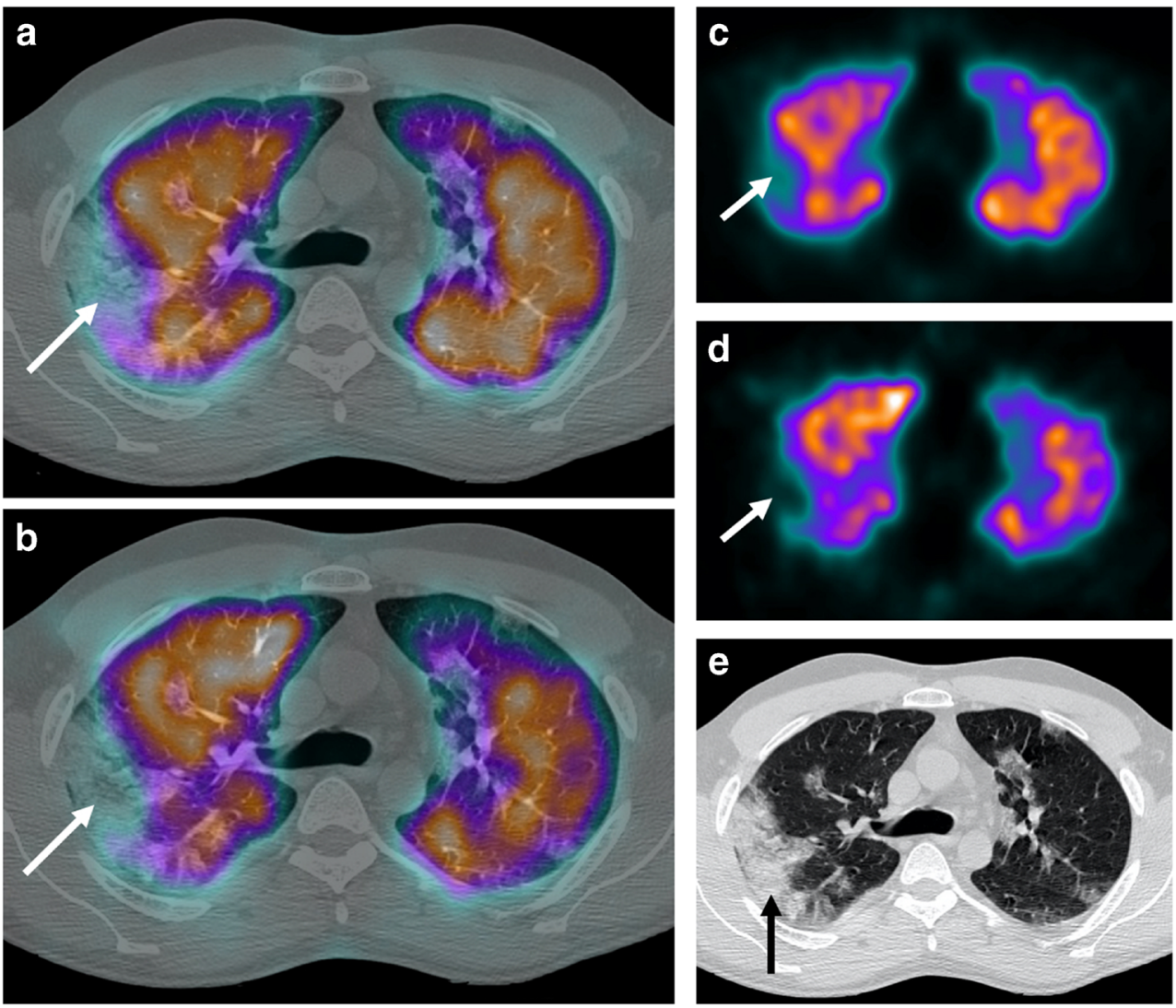

Moreover, patients hospitalized for COVID-19 pneumonia often have, in addition to bed rest and sepsis, intrinsic risk factors for thromboembolic disease (obesity, high age).

The diagnosis of thromboembolic disease therefore seems essential in the management of the patient.

COVID-19 is also associated with a significant risk of renal failure [9], which may contraindicate the injection of iodinated contrast agent on the CT scan as well as the allergy to iodinated contrast agents. In this case, pulmonary scintigraphy becomes the examination of choice for diagnosing PE.

In the five cases of COVID-19 patients that we have reported, we note different patterns and characteristics of the V/ Q SPECT/CT:

1) The pulmonary lesions of COVID-19 did not interfere with the diagnosis of thromboembolic disease.

2) The areas affected by COVID-19 on the CT scan were most often responsible for ventilatory defects with a relatively preserved perfusion, little or not diminished, particularly at an early stage of the disease with only ground glass opacities.

3) At an advanced stage of pneumonia, associating alveolar fillings and parenchymal anomalies of organized pneumopathy, the perfusion seemed more damaged with perfusional defects matched in ventilation.
There are several hypotheses regarding these areas of hypoperfusion:

- An adaptive mechanism with hypoxic pulmonary vasoconstriction and redistribution of the perfusion in adjacent well-ventilated areas [10].

- A destructive mechanism, with the occurrence of an alveolar destruction with involvement of the capillary walls, damaging the perfusion. At this stage, we can assume the onset of a pulmonary fibrosis which could also lead to an alteration of the perfusion.

- An embolism mechanism, with the occurrence of pulmonary infarction in areas of consolidation [11]. This hypothesis is unlikely since in patients with these patterns, no other embolic signs were found (no mismatched perfusion defects find on the V/Q SPECT/CT).

4) Areas of healthy parenchyma on the CT scan had an uptake of the tracers of perfusion (toggle of flow) and ventilation ("luxury ventilation"-in Technegas ${ }^{\circledR}$ and in Krypton) probably related to an adaptive mechanism and a redistribution of the perfusion and ventilation towards the healthy parenchyma.

The nuclear physician will have to pay attention to the technical parameters of the V/Q SPECT/CT, in particular to 

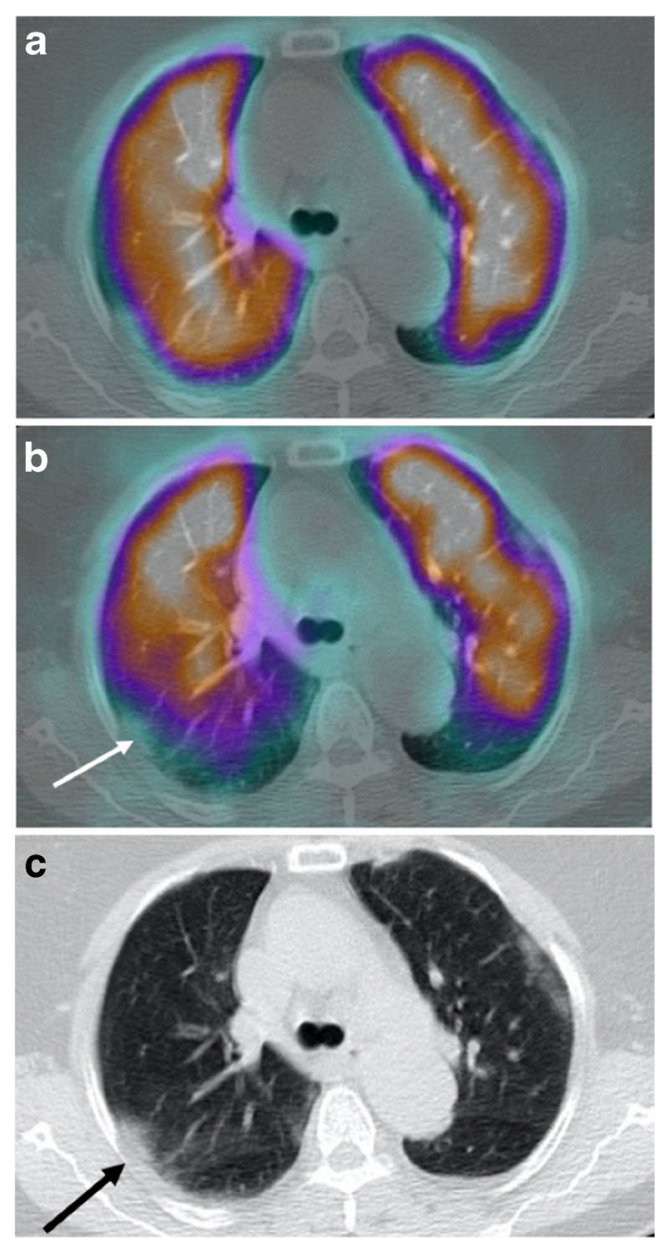

Fig. 5 a Axial fused perfusion SPECT and CT (185 MBq of Pulmocis®). b Axial fused ventilation SPECT and CT (148 MBq of Krypton $®)$. c Axial CT scan. Mismatched ventilatory defect in the posterior segment of the right upper lobe (white arrow), compared to ground glass on the scanner (black arrow)

the scanner settings, which may be able to detect a progression of COVID-19 lesions compared to previous examinations.

Recently, publications came out discouraging nuclear medicine physicians to use ventilation due to the risk of aerosol contamination [12]. However, to date, no case of crosscontamination has been described with the use of Krypton and Technegas ${ }^{\circledR}$. The French Society of Nuclear Medicine (SFMN) recommends maintaining V/Q scan with the ventilation to search for PE. According to its recommendations, the risk of contamination is extremely low [13]. Hygiene measures are obviously needed to limit the risk for healthcare workers as well as for patients (protective clothing, separate COVID+/COVID - circuits, cleaning of rooms, and equipment between each examination) [14].

Furthermore, performing a V/Q scan without ventilation might decrease its specificity and provide a risk of falsepositives [15]. In the current context of a pandemic, utility of ventilation data must be studied in an appropriate research with a retrospective interpretation of the V/Q SPECT/CT by two readers: one using perfusion and ventilation for diagnosing PE and the other using only perfusion and the CT scan, in order to have more information on the most efficient and secure method for diagnosing PE in COVID-19 patients.

$\mathrm{V} / \mathrm{Q}$ SPECT/CT not only is a tool allowing the diagnosis of pulmonary embolism in a single modality, but it can also, with the associated CT scanner, assess the degree of pulmonary involvement of COVID-19 while avoiding the risk of renal failure linked to the injection of iodinated contrast medium particularly to patients at risk.

Continuing to collect data will confirm the different patterns highlighted on the scintigraphy. In addition, in this pandemic context and facing a significant infectious risk, the utility of ventilation will also have to be specified.

Data availability Not applicable.

\section{Compliance with ethical standards}

Conflict of interest The authors declare that they have no conflict of interest.

Ethics approval - Informed consent was obtained for all patients.

- This series of cases was approved by the local ethics committee of the Centre Cardiologique du Nord, in Saint-Denis, Ile-de-France, France.

Code availability Not applicable.

\section{References}

1. Sohrabi C, Alsafi Z, O'Neill N, Khan M, Kerwan A, Al-Jabir A, et al. World Health Organization declares global emergency: a review of the 2019 novel coronavirus (COVID-19). Int J Surg. 2020 Apr;76:71-6.

2. Chen N, Zhou M, Dong X, Qu J, Gong F, Han Y, et al. Epidemiological and clinical characteristics of 99 cases of 2019 novel coronavirus pneumonia in Wuhan, China: a descriptive study. Lancet. 2020 Feb;395(10223):507-13.

3. Han H, Yang L, Liu R, Liu F, Wu K, Li J, et al. Prominent changes in blood coagulation of patients with SARS-CoV-2 infection. Clin Chem Lab Med CCLM [Internet]. 2020 Mar 16 [cited 2020 Apr 13];0(0). Available from: http://www.degruyter.com/view/j/ cclm.ahead-of-print/cclm-2020-0188/cclm-2020-0188.xml

4. Klok FA, Kruip MJHA, van der Meer NJM, Arbous MS, Gommers DAMPJ, Kant KM, et al. Incidence of thrombotic complications in critically ill ICU patients with COVID-19. Thromb Res [Internet]. 2020 Apr [cited 2020 Apr 13]; Available from: https://linkinghub. elsevier.com/retrieve/pii/S0049384820301201

5. Chen J, Wang X, Zhang S, Liu B, Wu X, Wang Y, et al. Findings of acute pulmonary embolism in COVID-19 patients. SSRN Electron J [Internet]. 2020 [cited 2020 Apr 13]; Available from: https:// www.ssrn.com/abstract $=3548771$

6. Ng KHL. Pulmonary artery thrombosis in a patient with severe acute respiratory syndrome. Postgrad Med J. 2005;81(956):e3.

7. Zhou F, Yu T, Du R, Fan G, Liu Y, Liu Z, et al. Clinical course and risk factors for mortality of adult inpatients with COVID-19 in Wuhan, China: a retrospective cohort study. Lancet. 2020 Mar;395(10229):1054-62. 
8. Tang N, Li D, Wang X, Sun Z. Abnormal coagulation parameters are associated with poor prognosis in patients with novel coronavirus pneumonia. J Thromb Haemost. 2020;18(4):844-7.

9. Pan X, Xu D, Zhang H, Zhou W, Wang L, Cui X. Identification of a potential mechanism of acute kidney injury during the COVID-19 outbreak: a study based on single-cell transcriptome analysis. Intensive Care Med [Internet]. 2020 Mar 31 [cited 2020 Apr 13]; Available from: http://link.springer.com/10.1007/s00134-02006026-1

10. Euler US v, Liljestrand G. Observations on the pulmonary arterial blood pressure in the cat. Acta Physiol Scand. 1946;12(4):301-20.

11. Worsley DF, Kim CK, Alavi A, Palevsky HI. Detailed analysis of patients with matched ventilation-perfusion defects and chest radiographic opacities. J Nucl Med. 1993;34(11):1851-3.

12. Zuckier LS, Moadel RM, Haramati LB, Freeman LM. Diagnostic evaluation of pulmonary embolism during the COVID-19 pandemic. J Nucl Med. 2020 May;61(5):630-1.

13. SFMN. Recommandations pour la réalisation de la scintigraphie pulmonaire dans le contexte d'épidémie due au virus Covid-19
[Internet]. Available from: https://www.sfmn.org/drive/CNP/ CODIV-19/Recommandations_GT-ExplorationsPulmonaires3003-2020.pdf. Accessed 30 Mar 2020.

14. Zhang X, Shao F, Lan X. Suggestions for safety and protection control in Department of Nuclear Medicine during the outbreak of COVID-19. Eur J Nucl Med Mol Imaging [Internet]. 2020 Mar 25 [cited 2020 May 14]; Available from: http://link.springer.com/10. 1007/s00259-020-04779-x

15. Bajc M, Neilly JB, Miniati M, Schuemichen C, Meignan M, Jonson B. EANM guidelines for ventilation/perfusion scintigraphy: part 1 . Pulmonary imaging with ventilation/perfusion single photon emission tomography. Eur J Nucl Med Mol Imaging. 2009;36(8):135670 .

Publisher's note Springer Nature remains neutral with regard to jurisdictional claims in published maps and institutional affiliations. 